\title{
An exploratory study using weblogs as a learning and assessment tool in a Public Relations course
}

\author{
Sheila Yvonne Jayasainan * \\ School of Communication, Faculty of Arts \& Social Sciences, Taylor's University
}

\begin{abstract}
The study investigates the usefulness of weblogs in evaluating the understanding and performance of Public Relations (PR) learners. The study also explored PR leaners' reactions towards using weblogs as a learning and assessment tool for their performance. Fifty undergraduate students from a private institution of higher learning in the Klang Valley participated in a semester-long weblog project. The task required students to complete eight weekly-writing reflection entries on the principles and practices of PR onto their individual weblogs. The results indicate that PR leaners' understanding of the weekly topics improved with the use of weblogs. Moreover, 98\% of the participants considered their blogging experience in PR-related topics positive. The majority of students believed that the weekly-writing reflections using weblogs constituted a good tool to showcase their learning process and help them reflect on their learning progress in a weblog-based environment. 96\% welcomed the idea of employing blogs as an assessment tool. These results carry pedagogical implications in the use of technology for performance and assessment of PR learners.
\end{abstract}

\footnotetext{
*Corresponding author: SheilaYvonne.Jayasainan@taylors.edu.my
} 


\section{Introduction}

The inclusion of technology in teaching and learning has changed the instructional strategies in classrooms. The passive teacher-centred learning approach has now shifted focus to a more student-centred learning, whereby students take up an active role in their learning process. Millennials (or Gen-Y; those born from the mid-1990s to early 2000s) have never known a world without technology. These millennials students have grown up in an environment that possesses unprecedented levels of media saturation and technology. Thus, their attitude towards education are unique. They rely on technology as an essential component to every aspect of their lives. Therefore, there's a growing perception amongst education leaders that the use of technology in the classroom is an effective way to connect and engage with these millennials (Sidek \& Yunus, 2012). As such, many higher learning institutions are finding new means to traditional methods in order to bridge the learning efficiency gaps of millennials.

The challenge to education leaders is to modernise teaching methods and create an educational experience that enables students to apply what they have learned in the classroom to the world around them. This trend is also being influenced by the educational teaching and learning methods in Malaysia. The Malaysian Government is encouraging and emphasising the need to incorporate multimedia technology into the curriculum (Mat, 2000 as cited in Neo \& Neo, 2010). This would facilitate the development of innovative modals that would enable higher learning institutions to better cater to the needs of the diverse types of students in today's university environment (Sidek \& Yunus, 2012).

Smith (2009 as cited in Sidek \& Yunus, 2012) states there has been an explosion of experimentation with weblogs or blogging in the classroom in the recent years. Educators believe there's a possibility of engaging students' interest using this technology. Weblogs, a popular form of personal web-publishing allow individuals to publish their thoughts, reflections and commentaries in the form of individual posts of varying lengths on a web page (Sharma \& Xie, 2008). Weblogs offer two advantages for reflection: whereby it supports students' ability to record and revisit experience which is crucial for reflective learning; and it engage students' in articulating their thoughts and feeling (by writing posts) which leads to students' understanding of content and subsequently encourages selflearning (Sharma \& Xie, 2008).

Although empirical research on weblogs use in higher learning institutions are relatively scarce, informal accounts from practitioners and researchers indicate that weblogs can be an important individual conversational learning space (Fiedler, 2003 as cited in Sharma \& Xie, 2008). Bartlett-Bragg (2003) found weblogs useful as it allows students the freedom of commenting, for publishing unconnected pieces of knowledge and as a space to record their self-learning. Williams \& Jacob's study found weblogs helpful in higher education whereby it has the potential to provide students with high level of independence while simultaneously providing opportunity for deeper interaction and exchange of information with peers (2004).

The examples cited above are amongst the few studies that cite empirical data in support of students' perceptions of weblogs, however none of them describes in detail the effectiveness of weblogs in evaluating PR learners' understanding and their perception of using weblogs as an assessment tool.

Thus, the purpose of this paper is to gauge PR learners' perception of and experiences with using weblogs as part of their learning process in a Malaysian higher institution classroom. By incorporating this student-centred learning approach coupled with using weblogs to provide a separate student-owned space, the paper hopes to assess the effectiveness of this approach to learning in a Malaysian higher institution classroom. 


\section{Literature Review}

\subsection{The rise of technology in the classroom}

Multimedia technology is an important component in enhancing the motivation and learning process of students (Neo \& Neo, 2010). With the availability of multimedia and Web 2.0 applications, students are able to utilise various applications such as a web-based learning and weblogs as tools in their learning. Therefore, educators have tried to incorporate these online technologies into the classroom environments to increase student satisfaction and learning. Currently, many educators are incorporating weblogs as part of their teaching and learning process as it allows students to publish and share information.

Weblog (or blog in short) is one of the most appealing Web 2.0 tools as it allows users to create personal journals and resource sites to share. The power of a blog lies in its' simplicity and the range of content it can profile on the web without a lot of technical understanding. In the classroom environment, blogging is found to be useful in improving students' critical thinking as the asynchronous mode of communication in weblogs allow students to think deeper before submitting their posts as it is viewed by a wider audience (Wang, 2005 as cited in Wang \& Woo, 2008). Besides, the use of weblogs in the classroom provides a safe and comfortable environment for students particularly introverted one to express their ideas freely and creatively.

In addition, students have the freedom to take ownership over their content; they can post, edit, delete and be creative by adding videos, images, infographics and others. By having the freedom to control, it allows students to explore beyond the norm and take more responsibility for their self-learning.

Other studies, however have shown mixed results. Students' weblog usage will not improve their learning without applying suitable content, scaffolding and strategies in the learning environment (Ellison \& Wu, 2008 as cited in Top, 2012). Furthermore, students did not consider peer comments valuable for their learning (Ellison \& Wu, 2008 as cited in Halic, Lee, Paulus \& Spence, 2010). Instead, reading other students' blogs is significantly more helpful than reading comments on one's own blog (Ellison \& Wu, 2008 as cited in Halic et al, 2010).

\subsection{Student-centred Learning}

Student-centred learning is a dominant educational learning approach, whereby students learn by actively participating in learning activities. They have greater freedom and control over choice of subject matter, learning methods and pace of study (Gibbs, 1992 as cited in Neo \& Neo, 2010). This suggest that learners can decide on their own learning approaches. Therefore, researchers have defined student-centred learning as active learning; learning of "doing" rather than of passive watching or listening (Neo \& Neo, 2010). In other words, students assume a high level of responsibility in their learning process and not solely depend on the educator's direction.

This is in-line with the constructivists claim that knowledge is constructed by students themselves rather than deriving it from educators (Jonassen, 1991 as cited in Wang \& Woo, 2008). Social constructivists further argued that knowledge is collaboratively constructed in a social context mediated by discourse; learning is then fostered through interactive and social activities such as information sharing, negotiation and discussion (Wang \& Woo, 2008). Thus, weblog basically provides an avenue for students to publish information and obtain feedback from others. 
Therefore, with the advent of technology in classroom and Web 2.0 applications, student-centred learning approaches are being implemented in various classroom environments especially in higher education in Malaysia.

\subsection{Using weblogs to engage students in reflection}

Many educators are using weblogs to promote interactivity and self-reflection in their students learning process. Blogs provide the space for individuals to express their opinions whereby bloggers are given a sense of personal empowerment and belonging to the learning community at large (Farmer, Yue \& Brooks, 2008 as cited in Neo \& Neo, 2010).

Weblogs provides a way of capturing the learning process. Students are able to externalise their thoughts through writing or visual representation in an ongoing manner. Posts in a weblog are organised in a reverse chronological order. By tracking the blog posting chronologically can help to identify how one constructs meanings over time in various subject matters (Fiedler, 2009 as cited in Wang \& Woo, 2008).

Interactivity is a major construct of a technology enhanced learning environment (Mollam, 2003 as cited in Wang \& Woo, 2008). The use of weblogs in the classroom to a certain extent promote learner-content interaction as the process of writing can naturally help students to think and reflect. When used in a learning environment, weblogs reflect students' understanding of a subject matter and the meaning associated with it (Linddell, Hubbard \& Werner, 2000 as cited in Wang \& Woo, 2008). Reflections is said to also have a positive effect on students' academic and personal development (Linddell, Hubbard \& Werner, 2000 as cited in Wang \& Woo, 2008).

The use of weblogs as part of a subject-matter offers students an effective way to publish and reflect on the content in a discursive manner. Thus, allowing students to make self-improvement progressively. In this learning process, the role of the educator is more likely to be a reviewer who reads the weblog content and gives comments and suggestions for improvement. In addition, by receiving feedback from readers, students can make improvements in their content.

In a study by Strampel \& Oliver (2007) states that students perceived blogging as a mean of offering them the ability to evaluate their own learning, to revise their thinking and to reflect. This evidence suggests that by writing about the learning, students were better able to see and understand their thinking and change their conceptions when necessary both important elements in higher levels of reflection and cognitive processing (Strampel, 2007).

Xie et al (2008 as cited in Halic et al, 2010) reported positive findings related to the effect of time on students' level of reflection: as time lapsed, the reflective thinking scores of students who continued blogging (either with or without feedback) increased.

\section{Methodology}

\subsection{Background}

A survey research design was selected to investigate students' perception of and experiences with using weblog in an undergraduate class in a Public Relations course at a private institution of higher learning in the Klang Valley. Students $(n=65)$; those taking the course as a core subject and those taking the course as an elective subject were assigned to engage in weblog reflections related to Public Relations (PR) concepts covered in the weekly lectures. During the course of their semester, each student was required to create an 
individual weblog and upload one post of 500 words per week for a period of eight consecutive weeks of a 14-week semester. Weebly was selected as a hosting provider for the weblog because it provides a much more reliable access and allows for creativity in the weblog design.

One of the reason weblogs was chosen as a requirement of this course was to encourage students to create an online portfolio of written work and also as a means of reflecting on their understanding of the weekly PR concepts taught during lectures. By using weblogs, these students were able to practice and enhance their writing skills, which is a crucial skill for a Public Relations student and future practitioner. Furthermore, the use of weblogs was also to build students' creative prowess with the use of images, videos, infographics etc. to support their writing reflections. This was the first time in this course that weblogs were used as part of the learning and assessment process.

\subsection{Participants}

The participants in this study were undergraduate students $(n=50), 32$ females and 18 males. The gender distribution of this sample was slightly uneven but comparable to the distribution of the overall student population in this Public Relations course where approximately $40 \%$ are male students and $60 \%$ are female students. The participants' ages ranged from 18 to 24 years. Most of the participants were in their Semester 3 (Year 2, Semester 1) of their undergraduate Public Relations degree.

\subsection{Instrument and Procedure}

The instrument included five items to record students' perception on their experiences of using weblogs as part of their learning and assessment process. The survey was administered online using Socrative Exit Ticket. Both open and close ended questions were asked to gauge students' perception and experiences of using weblogs in the classroom.

Responses recorded from students were anonymous. Data collection occurred during the last week of the 14-week semester. There was no course credit was given for completing this survey. The survey yielded a response rate of $98 \%$. Once the students completed their responses on the survey, the data was analysed.

Besides close ended questions, students were also asked several open-ended questions. These questions were used to garner feedback directly from the students themselves. Their comments will be shown together with the results of the survey. Their feedback was not edited or summarized. Figure 1 and Figure 2 are samples of these students' weblogs. 


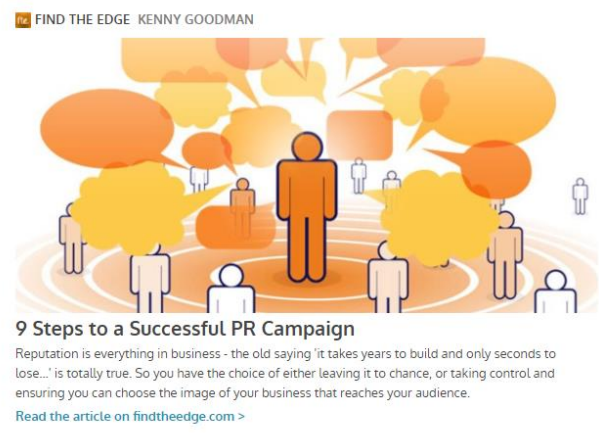

Figure 1. Sample of students' weblog

\begin{abstract}
Air Asia Foundation strive to develop life sustainability through social entrepreneurship. Anyone who dreams to tackle social problems and to improve communities can apply for this grant, successful grantees will be provided with funds and mentorship throughout the grant period (Air Asia Foundation, 2015)

Air Asia has funded various projects throughout ASEAN but my fauourite one was RAGS2RICHES. How did this project begin? In 2007, Reese Fernandez started her social enterprise Rags2Riches as soon as she discovered that the women in Payatas, Philippines largest poor communities whom artisans (craft worker) lived by earning only US\$0.20 cents per day scavenging through dumpsites for scrap pieces of fabric and turning them into handcrafted rugs! (Air Asia Foundation, 2015) She wanted to uplift the community out of poverty by creating a business that would develop life sustainability. However, Reese saw that Rags2Riches needed to expand its market and network in order to have a greater production stability.
\end{abstract}

Figure 2. Another sample of students' weblog

\title{
4 Results and Discussion
}

\subsection{Students' Experience and Satisfaction with using Weblogs for Learning and Reflection}

The majority of the participants in this study reported that their weblog experience was positive in this Public Relations course and it enhance their overall learning in particular helping them to think about PR concepts outsides of the classroom.

This is similar to the views of Churchill (2009 as cited in Halic et al, 2010), the current findings revealed that $98 \%$ had a positive experience with the weblog-supported learning environment and acknowledge the learning potential of weblog as a discussion medium. Students found that weblog offered them the opportunity to reflect on PR-course related concepts outside of the classroom and to share their different perspectives on the course material discussed during lectures. Some of the qualitative feedback from the participants are as follows: 
"I've learnt and understand more about Public Relations itself".

"I understand the vital aspects for a successful PR campaign".

"I learned how to manage my time doing the blog every week and also understand about the Public Relations industry even more".

"I understand audience engagement through the differences of media as a PR

\section{Practitioner".}

"I have learnt on how to analyze CSR campaigns and how to determine whether it was a successful one or not. Another thing that I learnt from this module is that, the structure of $P R$ and what a PR practitioner can do in an organization. I have also learnt how important $P R$ is to the world".

"I learned how to write better and more professionally from a PR standpoint and learned the importance of new media and how it affects the PR field and how I must be more adaptable".

These results are consistent with some qualitative findings on students' experiences of blogging as carried out by Paulus, Payne et al (2009 as cited in Halic et al, 2010) which found that students when blogging in an unstructured environment without discussion prompts or active facilitation by instructors offered multiple perspectives on the topic.

Furthermore, a previous study carried out by Sharma \& Xie (2008) found that blogging stimulated students thinking and learning by offering alternative perspectives related to the course content. This is similar to the current results where students carefully examine the current course content taught in lectures and extended their discussion outside the classroom in their weekly blogging activity. Overall, these activities engage critical thinking and reflection for students.

\subsection{Students' perception of the advantages and disadvantages with using Weblogs for Learning and Reflection}

The results showed that students view the use of weblog in their PR-related course as positive and beneficial to their learning and reflection needs. Their weekly reflections have helped them remember what they were taught throughout the semester and provided them recall information on activities already performed.

When asked to list some of the advantages of using weblogs for their course, some of the feedback by students include:

"It helped me in reviewing the lessons".

"I get to practice what I've learn on that topic and enhance the understanding of the topics".

"It indoctrinates discipline in the student and serves as a revision to the students".

"It helps me see my progress every week and let me know my understanding level about the topics as well". 
"Sharpening writing skills \& understanding of module”.

"It keeps me reading new articles and facts consistently and allows me to do research and extra readings. I have learnt a lot of things other than what has been taught in the lectures".

"It is beneficial as it refreshes my memory on each topic that we have learnt every week. It also helps us improve in our writing".

Besides, students were also asked their feedback on the disadvantages of using weblogs for their learning and reflection. Computer expertise emerged as a predictor of perceived learning. Neither previous experience with weblogs nor age or language used had any significant impact on perceived learning.

Computer expertise or technical competence which had previously been identified as a critical factor for success in online environments in a study by Soong et al, 2001 (as cited in Halic et al, 2010) supports the current finding that students' computer expertise influenced their perception of learning. Some of their feedback include:

\section{"The website is slightly hard to use". \\ "I don't really know how to design a website...." \\ "I would prefer Wix over Weebly because Weebly hates me".}

Besides the lack of computer or technical expertise, other disadvantages from the findings as indicated by the students are weblogging was time consuming and required them to conduct research prior to writing. Their feedback includes:

"It is time consuming and require a lot of effort in researching".

"Having trouble to do it weekly and having to research".

"Time needed for research".

"Time consuming as need to do it every week".

"The least beneficial part would be the duration of research needed for the task".

"Highly opinionated to my own perspective".

\subsection{Students' perception of using Weblogs as an Assessment Tool for a PR- course}

Since this is the first time weblog is used in the assessment of this PR course in an undergraduate level, the aspect of assessment was analysed. Students were asked for their feedback if the use of weblogs as an assessment tool was appropriate in this course. The findings revealed that $96 \%$ of participants felt that using weblogs for grading was appropriate and beneficial to them in this PR-course. Furthermore, students felt that using weblogs allowed them to have control of their assessment progress, to see improvement in their work and it was acceptable for them to make mistakes and learn from it.

Some of their qualitative feedback include: 
“...it helped me in learning the modules easier".

"Yes it helped with my critical thinking and polished up my research skills".

"Yes. It had help me improve my writing as a PR student...".

"It's a more friendly assessment for our demographic compared to exams".

"I can see improvement on my writing skills from the first week to the last week of reflection. There is an increase in my writing expression and I try to use new vocabularies in my reflection.

The impact of weblog effectiveness on the understanding of PR-related concepts has had a positive effect on the overall final grades of the participants. It is evident that their performance in this PR-related subject has improved from the previous semester whereby weblogs was not use as part of their assessment. The passing rate at the end of the semester for this subject was $94.74 \%$ with only two failures out of 65 students; showing a sharp increase of $15.34 \%$ pass rate from the previous semester [the overall pass rate from the previous semester was $79.4 \%$ ].

\section{Conclusion}

From the results of the research, the overall students experience and perception of using weblog in their learning process in a PR-related course in an undergraduate classroom proved to be effective in this study. The students were able to comfortably integrate weblogs into their learning process which had not being done in previous classes. The use of weblog in the classroom has helped them understand the subject-matter better and challenged them in their research and critical thinking skills; allowing them to give their best in their weekly reflections.

This study showed that the use of weblogs in a Malaysian undergraduate classroom was an effective instructional tool which could be used to enhance and engage students actively in their learning process. Hence, this technology-enhanced learning mode has a positive impact on students' learning especially these technology-savvy millennials and can serve as a viable option in a student-centred higher learning classroom.

Nevertheless, one of the limitations of this study is that it did not attempt to make comparisons between students who used weblogs and those who did not; even though such an analysis could provide further insights into students' perception of weblog effectiveness to support learning. Future research could investigate into students' attitudes towards peer feedback in a blended learning environment.

\section{References}

Bartlett-Bragg, A. (2003, December). Blogging to learn. The Knowledge Tree 4.

Halic, O., Lee, D., Paulus, T., \& Spence, M. (2010). To blog or not to blog: Student perceptions of blog effectiveness for learning in a college-level course. Internet \& Higher Education, 13, 206-213. 
Neo, T.K. \& Neo, M. (2010). A Study using web-logs or blogs as a tool for student-centred learning in a computer graphics course: A Malaysian perspective. The International Journal of Learning, 17(9), 77-86.

Sharma, P. \& Xie, Y. (2008). Student experiences of using weblogs: An exploratory study. Journal of Asynchronous Learning Networks, 12(3-4), 137-156.

Sidek, E.A.R. \& Yunus, M.M. (2012). Students' experiences on using blogs as learning journals. Procedia - Social \& Behavioural Sciences, 67, 135-143.

Strampel, K. \& Oliver, R.G. (2007). Using blogs in higher education: A pilot study on how online journaling can be effective in language learning. Proceedings Ascilite Conference Melbourne. Retrieved from http://www.ascilite.org.au/conferences

Top, E. (2012). Blogging as a social medium in undergraduate course: Sense of community best predictor of perceived learning. Internet \&Higher Education, 15, 24-28.

Wang, Q. \& Woo, H.L. (2008). Affordances and innovative uses of weblogs for teaching and learning. In Kobayashi, R (Ed), New Educational Technology (pp.183-199). NY: Nova Science Publishers.

Williams, J.B. \& Jacob, J. (2004). Exploring the use of blogs as learning spaces in the higher education sector. Australasian Journal of Educational Technology, 20(2), 232-247. 